\title{
A INSTABILIDADE DEMOCRÁTICA NA AMÉRICA LATINA DO SÉCULO XXI: OS CASOS DA ARGENTINA E DA VENEZUELA
}

\author{
João Carlos Amoroso Botelho \\ Demos (Grupo de Estudos da Democracia e de Política Comparada) da PUC-SP \\ E-mail: joaocarlosbotelho@hotmail.com
}

\begin{abstract}
Resumo
Este artigo se propõe a analisar as causas da instabilidade democrática nas democracias latino-americanas, a partir dos casos da Argentina e Venezuela. Procura verificar como a instabilidade ameaça a consolidação da democracia na América Latina.

Palavras-Chave: Democracia. Instabilidade Democrática. América Latina.
\end{abstract}

\section{Abstract}

This article analyzes the causes for democratic instability in Latin American democracies as found in Argentina and Venezuela. It attempts to verify how instability can endanger the consolidation of democracy in Latin America. Key-Words: Democracy. Democratic instability. Latin America

Argentina e Venezuela, consideradas como as nações latino-americanas com modelos de sistemas bipartidários consolidados (LAMOUNIER, 1992), entraram nos últimos anos em períodos de instabilidade democrática. $\mathrm{O}$ objetivo aqui é diagnosticar as causas dessas turbulências, que, em pleno século XXI, também atingem outros países da América Latina e são mais uma dificuldade para o desenvolvimento integral da democracia na região. Busca-se ainda contribuir com o debate sobre os meios de diminuir a possibilidade dessas ameaças ao regime.

A origem da instabilidade das democracias argentina e venezuelana pode ser identificada na combinação de crises econômica e de credibilidade de partidos e políticos. Em conseqüência da primeira situação, houve ainda a deterioração das condições sociais. Essa avaliação poderia dar por encerrada a questão não fosse por um aspecto que merece reflexão: por que, então, o Brasil, que enfrentou a mesma combinação de problemas no início dos anos 90, não descambou para a instabilidade democrática como seus dois vizinhos $^{1}$ ?

Essa pergunta, sem a intenção de incluir o Brasil como um terceiro objeto de análise neste estudo, é útil para ilustrar a hipótese de trabalho. Se

${ }^{1} \mathrm{O}$ entendimento é de que o processo de impeachment de Fernando Collor não chegou a gerar instabilidade democrática a variante priorizada neste artigo, mas apenas política. 
as crises mencionadas acima também existiram, em maior ou menor medida, no Brasil, o multipartidarismo consolidado no país e a tradição de sua democracia em contar com governos de coalizão são características que diferenciam o sistema político brasileiro do argentino e do venezuelano.

A partir da análise dos casos da Argentina e da Venezuela no século XXI, pretende-se defender aqui que multipartidarismo e governo de coalizão são dois aspectos que, em países com altos níveis de desigualdade socioeconômica e pobreza, contribuem para a manutenção da estabilidade democrática_entendida como o respeito às regras de alternância no poder. Essa hipótese também se restringe a um contexto mais recente das democracias, com eleições regulares, livres, minimamente limpas e de participação universal.

Lijphart (2003) inclui multipartidarismo e governo de coalizão entre os três primeiros traços definidores do modelo consensual de democracia, considerado por ele como o mais adequado a sociedades heterogêneas, já que, no majoritário, "as minorias que têm seu acesso ao poder sistematicamente negado irão sentir-se excluídas e discriminadas, podendo perder o senso de lealdade ao regime".

Esse mesmo diagnóstico de Lijphart sobre o potencial desestabilizador do modelo democrático majoritário em determinadas circunstâncias também vale quando, defende-se neste estudo, bipartidarismo e governo de partido único, duas características incluídas por ele entre as integrantes dessa variante, combinam-se com outras do regime consensual, como na Argentina e na Venezuela.

No próprio modelo consensual, multipartidarismo e governo de coalizão são dois passos a mais para permitir a distribuição dos recursos de poder entre os diferentes grupos. A presença de apenas um dos dois aspectos também não se mostra suficiente, como indicam os países priorizados neste trabalho, mas, entre os dois itens, é preferível o sistema multipartidário, que, segundo Lijphart, leva à aliança para governar. Tanto Argentina quanto Venezuela tiveram experiências de coalizões, mas que, sem a superação total do bipartidarismo, geraram um governo fraco politicamente ou um quadro inconsistente de alternativas partidárias.

O entendimento que se tem aqui de multipartidarismo é a existência de ao menos três siglas efetivas no sistema partidário _não se adota o cálculo formal do número de partidos efetivos; a definição deste trabalho leva em consideração a representatividade (quantidade de eleitos nos níveis federal, estadual e municipal) e a sustentação como força política de peso. Já governo de coalizão é encarado como a participação de integrantes de, no mínimo, duas legendas em cargos de primeiro escalão, respaldadas por apoio 
parlamentar e com ou sem a formalização de um acordo por meio da definição de um programa comum de gestão.

No médio prazo, porém, como também é possível extrair dos dois casos a serem analisados, mostra-se imprescindível que multipartidarismo e governo de coalizão estejam combinados com um avanço na melhoria das condições de vida da população. O nível de desenvolvimento socioeconômico do país interfere na sustentabilidade do seu regime democrático (PRZEWORSKI et al., 1997).

Sem evoluir satisfatoriamente nesses três aspectos, as democracias de Argentina e Venezuela viram também o protesto popular tornar-se um componente de suas práticas políticas. Depois de, ao longo da história dos dois países, ajudar a combater ditaduras, a mobilização da população nas ruas cobra hoje resultados dos regimes democráticos e tem sido capaz de derrubar ou reerguer presidentes.

Esta pesquisa predispõe-se ainda a encampar a avaliação de que, agora em discordância com Lijphart, o presidencialismo em si não é um entrave a um maior grau de consensualismo e ao conseqüente favorecimento da estabilidade da democracia em sociedades desiguais e pobres, e sim sua configuração, com a ênfase na presença ou não do bipartidarismo. Países como os latino-americanos, portanto, podem ser presidencialistas e mais consensuais, a exemplo do Brasil, estando assim menos sujeitos a turbulências do regime.

A instabilidade dos governantes é uma característica da história da América Latina. Sua origem remonta ao século XIX, quando as guerras de independência deixaram o legado de exércitos dispersos e Estados frágeis, incapazes de reprimir as investidas para a tomada do poder. Assim, os caudilhos, que haviam liderado facções armadas nas lutas emancipatórias, passaram a usar essas forças para perseguir suas ambições políticas. Nos 70 anos iniciais da República Dominicana independente, por exemplo, houve 23 revoltas vitoriosas. Nesse período, a guerra foi o único mecanismo de transferência de poder no país (ROUQUIĖ, 1984).

Também já é secular a disposição dos Estados Unidos em interferir nos processos políticos na América Latina. A primeira invasão de Cuba data de 1902. O mesmo ocorreu nos anos seguintes com Panamá, Nicarágua, Haiti e República Dominicana. Nessa época, a crescente importância norteamericana no cenário mundial levou o país a se considerar no direito de intervir militarmente na América Central e no Caribe, tida como uma "zona vital de segurança” (ROUQUIĖ, 1984).

A partir da revolução cubana de 1959, houve um aumento da ajuda militar dos Estados Unidos à América Latina, em recursos financeiros e no treinamento de pessoal, e um maior intervencionismo norte-americano na 
região. Com a implantação do comunismo em Cuba por Fidel Castro, o subcontinente virou uma área de preocupação dos Estados Unidos quanto à disseminação dos regimes de esquerda e ao avanço da influência da União Soviética, que rivalizava com os norte-americanos no contexto da Guerra Fria.

A América Latina contou ainda com uma extensa relação de governos e golpes militares. Em 1954, dos 20 países da região, 13 eram administrados por suas Forças Armadas. Apenas entre 1962 e 1966, foram nove tomadas de poder conduzidas por elas. Em 1980, dois terços da população latinoamericana viviam sob o domínio ou sob uma administração militar de fato (ROUQUIÈ, 1984).

O populismo completa o quadro de fatores históricos ligados à formação de uma tradição de instabilidade dos governantes na América Latina. Por seu estilo anti-sistema de fazer política, o líder populista tende a gerar turbulências esteja ou não no poder. Outro aspecto é que, ainda que não seja intrínseco a esse tipo de político recorrer ao golpe, representantes latinoamericanos usaram o expediente para continuar ou chegar ao governo. Contra o líder populista, também foi comum a ação preventiva diante da possibilidade de radicalização de esquerda.

Para Ianni (1991), é inerente ao populismo a submissão do Legislativo pelo Executivo. Assim, todo regime dessa natureza "tende a ser forte, semiditatorial ou simplesmente ditatorial”. A partir daí, o autogolpe é um desdobramento natural. $\mathrm{O}$ autor chega a enumerar líderes populistas da América Latina que recorreram à via golpista, com a ressalva de que isso não é um padrão.

Além dos fatores surgidos a partir do século XIX, é possível buscar na história do subcontinente outros até mais distantes para embasar a tradição de instabilidade dos governantes na América Latina, como esboça Borón (1996). "O molde autoritário do capitalismo latino-americano tem raízes muito profundas, que derivam de nosso passado colonial e da modalidade reacionária e dependente com a qual nossas sociedades se integraram ao capitalismo mundial".

Quando teve encerrado seu último ciclo de regimes militares, com a escolha de um presidente civil em eleições no Paraguai, em 1992, a América Latina deu, enfim, um passo significativo para relegar ao passado a tradição de instabilidade dos governantes. Esse avanço, no entanto, não resistiu à conjuntura política e econômica das próprias democracias implantadas.

Atingida pela crise da dívida externa na década de 80 , uma parte significativa do subcontinente viu-se constrangida pelos organismos internacionais de crédito como o FMI e o Banco Mundial a aderir entre o final dos 
anos 80 e o início dos 90, como condição para renegociar seus débitos, ao programa de reformas defendido a partir do Consenso de Washington. A aplicação desse modelo combinou o tripé reformista básico da desregulação, abertura de mercado e privatizações com a busca por equilíbrio fiscal e queda da inflação. Apesar de ter provocado uma euforia inicial, por causa da redução inflacionária e da geração de crescimento, o principal efeito das medidas, no longo prazo, foi a deterioração das condições de vida da maioria da população.

Esse programa neoliberal também tornou os governos que o adotaram na América Latina mais impotentes diante do processo de globalização, sobretudo em relação a sua variante que Fiori (1997) chama de financeira. As reformas desmontaram a capacidade estatal de regular os mercados e seus fluxos de capitais e geraram uma extrema dependência de empréstimos e investimentos externos. Assim, os países ficaram sujeitos a turbulências a cada crise surgida no cenário internacional e obrigados a manter os equilíbrios macroeconômicos como condição para ter credibilidade com os mercados, evitar sanções na forma de ataques especulativos e atrair recursos financeiros.

O surgimento do neoliberalismo como ideologia, segundo Anderson (1996), data de 1944, por meio de Friedrich Hayek. Sua expansão, porém, só começaria na década de 70, com a crise do modelo econômico do Estado de bem-estar social nos países ocidentais desenvolvidos. Assim, chegou ao poder, entre o final dos anos 70 e o início dos 80, com Margaret Thatcher na Inglaterra, Ronald Reagan nos Estados Unidos, onde a implantação do ideário neoliberal foi matizada pelo déficit público gerado com a retomada da corrida armamentista, e Helmut Kohl na Alemanha. Uma década depois, viria a expansão para o Leste Europeu e a América Latina, com a ressalva de que o Chile de Augusto Pinochet já havia abrigado a experiência precursora em nível mundial.

Para Anderson, o neoliberalismo alcançou seus objetivos, principalmente, em termos sociais e políticos. No primeiro caso, por ter promovido o aumento dos níveis de desemprego e desigualdade, entendidos como necessários para uma economia de mercado eficiente. No segundo, por ter disseminado a crença de que não havia alternativa aos seus princípios.

A Argentina e a Venezuela, que mais tarde viriam a enfrentar instabilidade democrática, estiveram, de acordo com Anderson, na linha de frente da onda de reformas neoliberais na América Latina a partir das posses, respectivamente, de Carlos Menem e Carlos Andrés Pérez em 1989. O segundo, porém, sofreu mais resistências políticas para a implementação das medidas, já que não contou com o antecedente de uma hiperinflação. 
"Um regime que cancela a cidadania política conseguida pela reinstauração da democracia com a 'descidadanização econômica e social' provocada pelo apogeu do neoliberalismo pode projetar uma superficial impressão de estabilidade, até que de repente se produz a débâcle”, prevenia Borón (1996).

Iniciados os anos 2000, a América Latina viu o começo de um período de instabilidade democrática logo no primeiro mês de 2000, com um golpe no Equador. No mesmo ano, houve uma tentativa no Paraguai. A partir de 2001, então, já no século XXI, ocorreram quedas de presidente na Argentina, na Venezuela, na Bolívia, no Haiti e novamente no Equador.

Transcorrida mais de uma década desde o final do último ciclo de regimes militares na América Latina e superados os períodos de transição na maior parte dos casos, as democracias políticas da região ainda não podem ser consideradas estáveis. Além dos resquícios golpistas e autoritários de suas elites política e econômica e de seus militares, hoje a população se tornou mais um dos juízes que podem decidir pela queda ou não dos presidentes latino-americanos.

Essa constatação não tem o objetivo de censurar ou referendar a realização de protestos. A questão aqui é saber como se configuram os quadros que levam à ocorrência das manifestações. Defende-se neste estudo que multipartidarismo, governo de coalizão e inclusão social contribuem para a estabilidade democrática.

Na Argentina e na Venezuela, os três aspectos, ou mesmo dois deles, não se combinaram efetivamente em suas trajetórias democráticas mais recentes. No Brasil, multipartidarismo e governo de coalizão sim, o que serviu até agora para evitar as ameaças ao regime, mas sem inclusão social. Na Bolívia e no Equador, porém, só os dois primeiros itens não foram suficientes, confrontados com, por exemplo, IDHs (Índice de Desenvolvimento Humano) situados entre os três piores da América do Sul _a disputa em torno dos hidrocarbonetos bolivianos, causa imediata da instabilidade, tem relação com a exclusão social, pois é difícil para uma população majoritariamente pobre aceitar a exploração de suas principais riquezas naturais por empresas estrangeiras. Nesses dois países, pesam também o descrédito político e o fator étnico, já que os grupos indígenas, que representam parcelas significativas das populações boliviana e equatoriana, ainda não foram devidamente incluídos como cidadãos e no sistema de representação.

Por outro lado, na Índia, multipartidarismo e governo de coalizão, que se reveza com gabinetes de partido único, também convivem com péssimos indicadores sociais e um IDH pior do que os de Equador e Bolívia, mas a democracia indiana tem passado incólumes as disputas na nação asiática são 
de outra origem, sobretudo fronteiriça e separatista.

Um terceiro exemplo bem-sucedido é o do Chile, onde a combinação de sistema multipartidário e gestão conjunta, com a vantagem de que o IDH chileno é o segundo melhor entre as nações sul-americanas, tem resultado igualmente em segurança para a ordem democrática. Outro país da América do Sul, o Uruguai, transitou de um bipartidarismo histórico para um maior número de siglas efetivas e viu isso ser acompanhado da estabilidade do regime.

Anastasia, Ranulfo e Santos (2004) formulam outra explicação para a instabilidade política nos países da América do Sul, sua ênfase difere da adotada aqui, que prioriza a ameaça à ordem democrática. Para eles, a principal causa de turbulências é a incongruência entre a agenda dos atores externos e a escolhida pelos eleitores nas urnas, mas não implantada pelo candidato vitorioso.

\begin{abstract}
Ou seja, a agenda preferida pelos cidadãos tem sido atropelada por outra, definida externamente e, muitas vezes, imposta. Como vêm sublinhando vários autores, as conseqüências de práticas de policy switches são perversas para a democracia na medida em que: 1. violam as preferências dos cidadãos, ao substituir a agenda por eles escolhida, nas urnas, por outra definida alhures [...]. As recorrentes crises de instabilidade política que assolam vários países da região podem ser relacionadas com a incompatibilidade entre as agendas interna e externa.
\end{abstract}

A administração Lula no Brasil e a primeira gestão Menem na Argentina, nas quais a incongruência entre promessas de campanha e medidas adotadas não deu origem a turbulências, enfraquecem esse argumento. Faz mais sentido considerar que o mais importante não é o descumprimento do prometido, e sim o sucesso ou não da agenda seguida, seja qual for.

Os períodos que mais interessam a este trabalho são os dos governos de Fernando de la Rúa na Argentina (1999-2001) e Hugo Chávez na Venezuela (1999-2007), com ênfase nos processos que culminaram na queda dos dois presidentes, provisória para o venezuelano e definitiva para o argentino, respectivamente em dezembro de 2001 e em abril de 2002. No caso da Argentina, não chegou a configurar-se um golpe de Estado, mas uma derrubada, distinção essa que vai ser aprofundada ao longo do texto. Já no da Venezuela, sim, houve um golpe, em conformidade com o modelo que se tornou clássico na história da América Latina, apesar de algumas peculiaridades importantes.

As trajetórias democráticas recentes dos dois países têm como principal traço em comum o bipartidarismo. Na Argentina, alternam-se na Presidência desde a reinstauração da democracia, em 1983, o PJ (Partido 
Justicialista), que é a legenda do peronismo, e a UCR (União Cívica Radical). Na Venezuela, a AD (Ação Democrática) e o Copei (social-cristão) revezaram-se de 1958 até 1993, quando Rafael Caldera, que já havia sido presidente pelo Copei, reelegeu-se por uma coligação de partidos menores. Se o critério for mais rigoroso, pode-se afirmar que a predominância de $\mathrm{AD}$ e Copei só terminou mesmo em 1998 com a eleição de Chávez, um político sem ligação com as forças tradicionais.

A gestão De la Rúa foi a primeira experiência de um governo de coalizão na Argentina desde a redemocratização e terminou em fiasco absoluto, com a renúncia do presidente, após fortes protestos populares. A Aliança pelo Trabalho, pela Justiça e pela Educação era composta desde 1997 por UCR e Frepaso, uma terceira força surgida em 1994, e já havia vencido as eleições legislativas no ano de sua formação. As causas apontadas no início para a instabilidade democrática, crises econômica e de credibilidade de partidos e políticos_estiveram fortemente presentes no caso argentino. Dois meses antes da queda de De la Rúa, as eleições legislativas de 2001 tiveram 13,23\% de votos nulos e 10,76\% de votos em branco. A situação econômica, então, era periclitante, com o país à beira da moratória de sua dívida externa e as condições sociais em franca decadência.

A decretação do corralito (o bloqueio de depósitos bancários) e, a seguir, a do Estado de sítio, em 19 de dezembro de 2001, foram as medidas que lançaram a classe média às ruas, em companhia das camadas mais baixas e de agitadores políticos profissionais, que já participavam de saques. Um dia depois, De la Rúa, isolado politicamente e pressionado pelos protestos, acabou renunciando.

A coalizão liderada por ele nunca chegou a valer-se desse nome. O vice Carlos Chacho Álvarez, da Frepaso, renunciou logo no primeiro ano de mandato, após assumir o papel de levar adiante denúncias de suborno a senadores na aprovação de um projeto governista e não se sentir apoiado por De la Rúa.

A Aliança enfrentou problemas de coesão desde sua formação. No curto período entre seu surgimento, em 1997, e a vitória nas eleições presidenciais de 1999, ela não foi capaz de institucionalizar mecanismos de concertação (NOVARO, 2002). Também não tinha uma liderança forte na qual se apoiar. A coalizão prejudicava-se ainda pela linha contrária às velhas práticas políticas em que a Frepaso havia se afirmado, algo que a centenária UCR não pretendia encampar de fato. Isso gerava contradições internas, que atingiram o ápice na renúncia de Chacho Álvarez, e dificuldades para a negociação com o PJ e líderes sindicais.

A administração De la Rúa foi um exemplo de governo fraco 
politicamente, em razão de sua própria natureza e da magnitude dos desafios que teve de encarar, reticente em contrariar interesses e incapaz de obter um acordo concreto de governabilidade com a principal força de oposição, que tinha a maior bancada no Senado. Para dificultar a via da negociação, o peronismo vinha de uma derrota e estava muito dividido, além de, diante do tipo de tradição bipartidária da democracia argentina, não ter predisposição para a colaboração.

Diante da magnitude da crise que De la Rúa teve de administrar já como legado da gestão Menem (1989-1999), nem a incorporação ao governo de mais uma sigla, a de Domingo Cavallo, nomeado para o Ministério da Economia, foi suficiente para amenizar a situação. Pelo contrário, pois o exministro menemista acabou por aglutinar os setores da oposição, mesmo a interna, em torno da exigência de sua demissão. A ascensão da Frepaso também não chegou a representar a consolidação de um sistema multipartidário na Argentina, já que a durabilidade das terceiras e quartas forças como partidos efetivos continuaria a ser curta, como a rápida derrocada da própria Frepaso mostraria.

$\mathrm{Na}$ Venezuela, que tem a democracia mais duradoura da América do Sul na atualidade, a instabilidade do regime não está ligada ao imobilismo do presidente, como na Argentina, e sim ao decisionismo e à concentração de poderes. A gestão Chávez, porém, não foi a única da história política recente do país a enfrentar turbulências. A instabilidade já havia ressurgido no final da década de 80. Em 1989, um pacote de medidas neoliberais anunciado por Carlos Andrés Pérez (AD) logo no início de seu segundo mandato, depois de prometer na campanha que não faria isso, gerou distúrbios generalizados no país, por causa do aumento do preço da gasolina e, em conseqüência, do custo do transporte.

Além dessa motivação mais imediatista, é importante descrever o contexto em que se deram os protestos, que tiveram um saldo oficial de 270 mortos. A Venezuela é o oitavo maior produtor mundial de petróleo e, portanto, um país no qual a população é acostumada a pagar pouco pela gasolina. Os venezuelanos também viam a crise da dívida externa e a queda do preço do petróleo minarem a capacidade de o Estado sustentar os sistemas de prestação de serviços básicos e de distribuição de benefícios. Recentemente, em 1983, ainda havia ocorrido uma desvalorização da moeda, que, até então, tinha uma cotação razoável frente ao dólar. Por último, o pacote neoliberal de Carlos Andrés Pérez não teve, como na Argentina e no Brasil, a antecedência de uma hiperinflação, que contribui para desfazer resistências. Nem o presidente pôde culpar a administração anterior pelas dificuldades, já que sua eleição havia mantido a $\mathrm{AD}$ no poder. 
No governo Carlos Andrés Pérez, a crise política somou-se ao descalabro econômico. Em 1992, o presidente foi alvo de duas tentativas de golpe militar_a primeira, liderada pelo então tenente-coronel do Exército Hugo Chávez. No ano seguinte, o governante venezuelano ainda sofreu o impeachment, acusado de corrupção. Ou seja, estava configurado o quadro das crises econômica e de credibilidade de partidos e políticos. Nas eleições presidenciais de 1993, com mais do que o dobro de abstenção em relação à edição anterior, pela primeira vez o vencedor foi nem da AD nem do Copei.

A instabilidade democrática voltou com a gestão Chávez, iniciada em 1999. A partir de então, o novo presidente começou a ter de lidar com as duas crises que persistiam e que haviam contribuído para sua vitória e adotou uma postura de confrontação com as elites, acusadas por ele de serem as responsáveis pela situação da Venezuela. Com isso, três anos depois, acabaria deposto por um golpe civil-militar e permaneceria afastado durante cerca de 48 horas. Chávez acumulou decisões e inimigos em diversas frentes, a partir de uma ideologia de que era necessário refundar o país, corrompido pelas práticas políticas anteriores, e levar adiante sua revolução bolivariana.

A pregação desse mito refundacional é uma das características que liga Chávez a líderes populistas do passado da América Latina. O nome do partido chavista, MVR (Movimento Quinta República), é uma alusão à idéia de que era necessário fundar uma nova República. Outro traço que relaciona o presidente venezuelano ao populismo é sua atuação no incentivo a uma participação política mais ativa das classes baixas. Essa participação é entendida mais como uma busca do ativismo cívico, mediado pelo líder, do que como um estímulo à filiação partidária _vide as freqüentes convocações oficiais a manifestações de rua e os círculos bolivarianos (organizações comunitárias, incentivadas pelo Estado, para a sustentação política e a atuação conjunta em relação à prestação de serviços públicos). Por outro lado, o chavismo e o governo que conduz não podem ser definidos como o resultado de uma aliança de classes, o que os diferencia dos regimes populistas latino-americanos descritos por Ianni (1991).

Uma visão negativa da política e da democracia tradicionais determinou a maneira como Chávez lidou com a crise de credibilidade de partidos e políticos. Sua ascensão à Presidência foi como um líder carismático e antisistema, que fez campanha em nome da substituição da velha classe política corrompida. Já seu partido, uma palavra que, por sinal, desapareceu da Constituição idealizada pelo chavismo, é um movimento personalista com fins, sobretudo, eleitorais. O MVR, por exemplo, continua a ter Chávez, inclusive formalmente, no topo de sua estrutura hierárquica, apesar do crescimento registrado desde as eleições de 1998 e de administrar hoje 16 das 24 
unidades da federação.

Outra característica da visão política do presidente venezuelano é a valorização da participação militar: a nova Constituição deu aos integrantes das Forças Armadas o direito de votar; o primeiro escalão de governo é recheado de militares; e as tropas são freqüentemente chamadas a colaborarem na prestação de serviços básicos e em trabalhos de assistência emergencial.

O decisionismo de Chávez atingiu seu ponto alto com o anúncio em novembro de 2001 de um pacote de 49 decretos, emitido por meio da Lei Habilitante_uma autorização concedida pela Assembléia Nacional para que o presidente possa legislar sem a interferência da Casa. No mês seguinte, as principais associações de trabalhadores e empresários convocaram a primeira greve geral contra a administração Chávez.

Nesse momento, a mídia também já fazia parte da aliança antichavista. Em abril de 2002, quando Chávez foi deposto, o grupo contou ainda com a atuação decisiva de setores militares e, no mínimo, a anuência do governo George W. Bush aos planos golpistas. Consumada a deposição, os Estados Unidos deram apoio ao presidente empossado, o empresário Pedro Carmona.

Desde os anos 80 , propostas de reforma institucional vinham em processo de discussão e aprovação na Venezuela. A mais importante a ser implantada foi a eleição para governador a partir de 1989 _até então, o presidente fazia as indicações. Isso abriu a possibilidade do surgimento de novas lideranças, mesmo nas legendas tradicionais, o que chegou a ocorrer, mas, como a crise política já se manifestava, a renovação acabou prejudicada. No último período presidencial antes de Chávez eleger-se, chegou a haver formalmente um governo de coalizão, mas sem que um sistema multipartidário já tivesse se afirmado.

Com a eleição de Chávez, o bipartidarismo de fato encerrou-se. O que passou a se enfraquecer, por outro lado, foi o governo de coalizão. Apesar de ter sido eleito por uma coligação partidária, o presidente venezuelano não abre muito espaço em seu ministério para integrantes das outras forças e não tem como política a valorização dessa participação. $\mathrm{O}$ estilo de administrar de Chávez também contribui para que a variedade atual de siglas transformese, na prática, num modelo bipolar_pois são dois pólos, e não dois partidos_e de jogo de soma zero. Com o nível de confrontação e, conseqüentemente, de polarização que se instaurou no país, acabam por só existir a situação e a oposição, ou os chavistas e os esquálidos, como os primeiros chamam os oposicionistas.

Se o bipartidarismo e as crises econômica e de credibilidade política são aspectos em comum no desenvolvimento dos processos de instabilidade democrática na Argentina e na Venezuela, há uma diferença significativa 
entre os dois casos. No venezuelano, essa perda de credibilidade implicou no redesenho dos sistemas político e partidário e no fortalecimento e na eleição de um líder que não pertencia à classe política tradicional, enquanto no argentino, isso não ocorreu. $O$ peronismo e a UCR continuam a ser as duas principais forças, e o presidente eleito após os protestos por "que se vayan todos" foi Néstor Kirchner, que era governador pelo PJ havia 12 anos.

Como se explicam esses resultados opostos nas respectivas eleições presidenciais? Pela interpretação deste estudo, de duas maneiras principais, que se complementam. Em primeiro lugar, o peculiar processo de escolha do candidato peronista teve um efeito de renovação. Com três candidaturas surgidas das fileiras do partido, as diversas correntes internas do peronismo puderam estar representadas na disputa e, ao mesmo tempo, sem que nenhuma tivesse o direito de carregar o nome da legenda. A segunda explicação é que, na Argentina, não houve o fortalecimento de um líder carismático e anti-sistema político, como Chávez, que pudesse canalizar o voto de protesto contra a classe política. Isso é reforçado pelo fato de que os argentinos havia se frustrado recentemente ao apostar numa força com um discurso contra os políticos tradicionais, a Frepaso.

Os casos argentino e venezuelano permitem, portanto, que se extraia a hipótese de que a engenharia institucional de linha consensualista e a inclusão social, em países com altos níveis de desigualdade socioeconômica e pobreza, contribuem para a sustentabilidade da democracia a longo prazo. Fraca ou forte, uma administração com poucos canais de negociação e sem mecanismos de contrapeso fica mais sujeita à radicalização dos conflitos e, em conseqüência, ao desrespeito às regras de alternância no poder. Multipartidarismo e governo de coalizão interferem para que haja menos possibilidade de turbulências do regime em sociedades desiguais, abrindo mais espaço para que os excluídos do sistema político possam participar dele, e não contestá-lo. No médio prazo, porém, esse desenho institucional tende a ser insuficiente para evitar a instabilidade democrática se não for combinado com a diminuição da exclusão social.

\section{REFERÊNCIAS}

ANASTASIA, Fátima; RANULFO, Carlos; SANTOS, Fabiano. Governabilidade e representação política na América do Sul. Rio de Janeiro: Fundação Konrad Adenauer UNESP, 2004. v. 1.208 p.

ANDERSON, Perry. Balanço do neoliberalismo. In: SADER, Emir; GENTILI, Pablo (Org.). Pós-neoliberalismo. Rio de Janeiro: Paz e Terra, 1996. 
BORÓN, Atílio. A sociedade civil depois do dilúvio neoliberal. In: SADER, Emir; GENTILI, Pablo (Org.). Pós-neoliberalismo. Rio de Janeiro: Paz e Terra, 1996. p.63-118. Carmona Estanga, Pedro. Mi testimonio ante la historia. Caracas: Actum, 2004. FIORI, José Luís. Os moedeiros falsos. Petrópolis: Vozes, 1997.

IANNI, Octavio. A formação do estado populista na América Latina. Rio de Janeiro: Civilização Brasileira, 1991.

LAMOUNIER, Bolívar. Estrutura institucional e governabilidade na década de 90. In: REIS VELLOSO, João Paulo dos (Org.). O Brasil e as reformas politicas. Rio de Janeiro: José Olympio, 1992.

LIJPHART, Arend. Modelos de democracia. Desempenho e padrões de governo em 36 países. Rio de Janeiro: Civilização Brasileira, 2003.

NOVARO, Marcos (Org.). El derrumbe político en el ocaso de la convertibilidad. Buenos Aires: Norma, 2002.

PRZEWORSKI, A.; ALVAREZ, M.; CHEIBUB, J. A.; LIMONGI, F. O que mantém as democracias? Revista Lua Nova, São Paulo, n. 40/41, p 113-135, 1997.

ROUQUIÈ, Alain. O Estado militar na América Latina. São Paulo: Alfa-Ômega, 1984. 
